\title{
A pesquisa em livros didáticos de ciências e as inovações no ensino
}

\author{
Paulo Sérgio Garcia ${ }^{1}$ \\ garciaps@usp.br
}

\author{
Nelio Bizzo ${ }^{2}$ \\ bizzo@usp.br
}

\section{Resumo}

Este estudo tem o objetivo de analisar a pesquisa sobre os livros didáticos de ciências (LDC) no Brasil e em alguns países e paralelamente relacionar esses resultados com as possibilidades de inovação no ensino. Foram analisados 77 estudos de 24 países. Nesses artigos, observamos os objetivos do estudo, o tipo de metodologia utilizada, a área de estudo e o assunto investigado, o número de pesquisadores envolvidos, o nível educacional do estudo e a nacionalidade. Os resultados mostraram que a maioria dos estudos dos outros países $(86,9 \%)$ e $90 \%$ do Brasil tinham o foco nos conteúdos do LDC. Essas pesquisas estavam mais concentradas na área de biologia $(42,3 \%)$ e centralizadas no nível secundário. Os pesquisadores utilizaram principalmente a metodologia qualitativa. A maioria dos estudos analisados era da França, Tunísia e Brasil. Os resultados deste estudo são relevantes para nortear futuras pesquisas em relação a esse material.

Palavras-chave: Livro didático de ciências; ensino de ciências; pesquisa em livros didáticos.

1 Doutor em Educação - Faculdade de Educação da Universidade de São Paulo (USP).

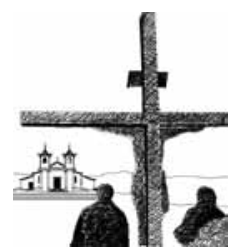




\section{Introdução}

O livro didático (LD) se constitui num objeto que envolve grandes debates por parte dos professores, especialistas, pais, docentes de universidades, entre outros, por sua relevância no ensino de ciências. No entanto, ainda não dispomos de muitas pesquisas sobre toda sua cadeia de desenvolvimento, envolvendo agentes e usuários desde a elaboração, fabricação, modos de difusão, financiamento até sua utilização. Essas informações são relevantes e úteis no sentido de promover inovações no ensino de ciências (EC).

Em alguns aspectos, as pesquisas sobre o LD já avançaram, trazendo contribuicões significativas. Pesquisadores já agruparam informações valiosas como, por exemplo, aquelas que descrevem o livro didático como um instrumento de poder a serviço de alguma ideologia (CHOPPIN, 2004); ou que consideram o livro didático de ciências (LDC) como uma produção humana e, portanto, cultural, englobando vários discursos (MARTINS, 2003); como o principal instrumento norteador do trabalho do professor, dirigindo e controlando de certa forma o currículo, os conteúdos, as relações didáticas, as práticas de aprendizagem e também a avaliação no ensino de ciências (GAYAN; GARCIA, 1997; BIZZO, 2007; BIZZO et al. 2007); e como o recurso mais utilizado no EC pelos professores (CARNEIRO; SANTOS; MOL, 2005).

O livro didático de ciências tem sido estudado em diferentes partes do mundo e, segundo Taskin (2007), essas pesquisas têm sido realizadas a partir de quatro grandes categorias que se relacionam aos conteúdos, às concepções educacionais, à apresentação visual e à linguagem contida no material. No entanto, Choppin (2004) afirma que a maioria dos trabalhos realizados podem ser agrupados em duas grandes categorias: 1) aquelas em que o livro didático é concebido como um documento histórico em que são analisados os conteúdos em busca de informações estranhas ao livro (forma de apresentação de determinados conteúdos, representação ideológica de um determinado tempo) 
ou as que se relacionam exclusivamente com o conteúdo ensinado; 2) aquelas que consideram o livro como um objeto físico (deixando de lado os conteúdos) e analisam questões como fabricação, comercialização, distribuição ou usos do material.

No Brasil, estudos anteriores têm mostrado que a maioria das contribuições das pesquisas advindas do LDC relaciona-se à área de conteúdos. Elas centralizam-se em conteúdos focados nas análises de conceitos, investigando, por exemplo, questões sobre os erros conceituais, a ideologia contida nos materiais, a imagem da ciência (FRACALANZA, 1993; CASSAB, 2003; FERREIRA; SELLES, 2003; CARNEIRO; SANTOS; MOL, 2005).

No entanto, por outro lado, poucos estudos têm se voltado para a compreensão de outros aspectos tais como: desenvolvimento histórico do material, edição escolar (a questão do mercado e dos produtos), relação do livro didático com a esfera escolar, escolha do livro pelos professores, recepção e uso por parte dos estudantes, relação dos docentes com o material, formação de professores para o uso, modos de uso na sala de aula e possíveis formas de inovação no ensino.

A falta de pesquisas sobre esses outros aspectos do LDC representa uma barreira para inovações no ensino de ciências e para a aprendizagem dos alunos na medida em que pesquisas desenvolvidas poderiam alavancar inovações e mudanças.

Neste estudo, pretendemos analisar a pesquisa sobre o livro didático de ciências em alguns países, incluindo o Brasil, com o intuito de verificar as regularidades, semelhanças e diferenças existentes nos processos de investigação. Paralelamente, almejamos relacionar esses resultados às possibilidades de inovação no ensino.

\section{O livro didático de ciências e as inovações no ensino}

Os pesquisadores já fizeram grandes progressos em descrever e relatar valiosas informações em relação ao livro didático. Choppin (2004), por exemplo, mostrou que o livro pode ser considerado

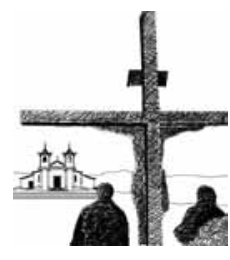


um instrumento de poder, servindo a uma ideologia. Isso, entre outras razões, faz com que muitos países exerçam algum tipo de controle sobre ele. Devido à complexidade do livro, os governos de muitos países no mundo exercem algum tipo de controle sobre o seu desenvolvimento, financiamento, distribuição e, em muitos casos, até mesmo sobre seus usuários.

Esse controle, às vezes, é político e ideológico, outras, é justificado para fins científicos ou pedagógicos. No Brasil, o Ministério da Educação e Cultura (MEC) avalia, através de seus especialistas, as obras submetidas pelas editoras e publica resenhas dos livros aprovados em um "Guia do livro didático", que chega até as escolas públicas brasileiras. Nesse processo, os professores são os agentes que selecionam os livros que desejam receber de forma gratuita em suas escolas, para utilização de seus alunos (BIZZO, 2007). Nesse processo, o MEC investiu, entre 2009 e 2010, quase dois bilhões na compra de livros para a educação básica (FNDE, 2011), valores que só são superados por programas de merenda escolar (FNDE, 2010).

A pesquisa já demonstrou que o LD é um objeto de estudo altamente complexo e envolve agentes e usuários em uma cadeia que vai desde a elaboração, fabricação, autorização, modos de difusão, financiamento, procedimentos de seleção até a utilização do material. O livro, portanto, situa-se, como afirmou Choppin (2004), na confluência de múltiplas interações, por vezes conflituosas, entre os agentes e os usuários. Dessa forma, ele constitui-se em um importante indicador de forças que se formam num dado momento social. Segundo o mesmo autor, o LD pode ser considerado um elemento cultural ou ideologico, servindo, dentre outras coisas,

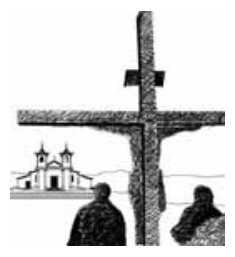
para a unificação nacional e para a uniformização linguística, constituindo-se num instrumento de poder que influencia crianças e adolescentes, na medida em que os livros didáticos são reproduzidos e distribuídos em todo o território de um país.

As pesquisas de Martins (2003) também já mostraram que o livro didático de ciências caracteriza-se como um objeto cultural 
situado, dentre outros, entre o discurso científico, pedagógico e midiático, envolvendo uma forma de negociação entre autor, cientista, professor, aluno e pais.

O livro didático como uma produção humana serve a diversos discursos de seus múltiplos agentes e usuários, situa-se entre diferentes forças, reúne parte do imenso conhecimento produzido pela humanidade, transmitindo informações verbais e não-verbais. Ele está envolvido por teorias educacionais e científicas, está impregnado de ideologias e, portanto, tanto pode formar como deformar aqueles que fazem uso dele. O LD exerce ainda um papel importante na construção do conhecimento dos alunos, carrega as marcas do discurso científico e escolar e, dessa forma, pode ser considerado um objeto cultural localizado num determinado tempo.

Dados de outros estudos também já nos mostraram que o LDC se constitui na principal ferramenta utilizada pelos professores em suas aulas. A centralidade do livro nas aulas (CARNEIRO; SANTOS; MOL, 2005; BIZZO, 2007) mostra a importância atribuída pelos professores a esse material, incluindo seu papel estruturante e estruturador nas atividades em sala de aula (MARTINS, 2003), ou seja, o professor a partir do LDC organiza as tarefas, os trabalhos e muitas vezes as pesquisas a serem executadas por seus alunos. O livro assume também uma posição de elemento controlador do currículo (GAYAN; GARCIA, 1997; BIZZO, 2007; BIZZO et $a l, 2007)$, pois para muitos professores, ele dirige os conteúdos a serem trabalhados no dia a dia.

Por sua importância em relação sobretudo à aprendizagem dos alunos, tem crescido o número de pesquisas sobre o LDC em várias partes do mundo. Em 2007, por exemplo, aconteceu um encontro internacional sobre o LDC (International meeting "critical analysis of school science textbook") promovido pela Internacional Organization for Science Techology Education (IOSTE), na Tunísia. O evento reuniu pesquisadores de muitos países. No contexto europeu, o projeto de investigação intitulado: Biohead-Citizen - Biology, Health and Environmental Education for better Citizenship é outro exemplo da

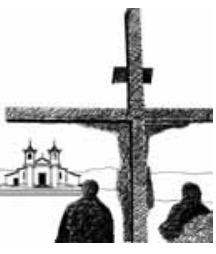


importância dos livros didáticos de ciências. O projeto funciona a partir de uma análise comparativa de diferentes elementos dos LDC de 19 países.

No Brasil, a pesquisa acadêmica sobre o LDC cresceu muito nas últimas décadas. Dados de Fracalanza e Megid Neto (2006), tendo como objeto de análise os trabalhos sobre o LDC conforme os períodos em que esses foram produzidos, mostraram que entre as décadas de 1970 e 2000 foram produzidos 76 trabalhos entre teses, dissertações e projetos de ensino.

Em muitas partes do mundo, o LDC tem sido analisado. Por exemplo, nos Estados Unidos, Hubisz (2003) avaliou os livros didáticos utilizados no ensino fundamental II (elementary school) e identificou, entre outras coisas, erros conceituais, ilustrações inadequadas, discussão inapropriada para a faixa etária e, em algumas edições, a inexistência de atividades experimentais. No contexto europeu, Knain (2001) realizou estudos com livros didáticos na Noruega e revelou que os aspectos ideológicos necessitavam de uma análise mais cuidadosa. Ele mostrou que a imagem da natureza da ciência descrita para estudantes nos materiais mostravam os cientistas trabalhando de forma individual e realizando descobertas através de experimentos.

Também na Europa, alguns dos aspectos mais estudados no LDC relacionam-se, entre outras coisas, às abordagens de conceitos básicos de biologia, que podem fornecer informações sobre os tipos de interações entre o conhecimento científico, as práticas sociais e sistemas de valores (BERNARD; CLÉMENT, 2005); aos obstáculos didáticos que possam surgir entre os alunos devido à manutenção do foco tradicional (CLÉMENT, 2005); ou à geração desse mesmo tipo de obstáculo devido ao uso de imagens inadequadas ou enganosas (CARVALHO; SILVA; CLÉMENT, 2005). Na América do Sul, na Venezuela, Niaz et al. (2002) mostraram que a abordagem tradicional de livros didáticos de química destaca detalhes experimentais, no entanto, ignora o modo como a ciência é construida. Na análise desses autores, os livros não incluiam as 
perspectivas histórica e filosófica, aspectos que poderiam tornar a aprendizagem mais significativa para os alunos.

No contexto brasileiro, alguns estudos têm demonstrado que a maioria das pesquisas sobre o LDC se concentra no conteúdo das ciências. Essas pesquisas têm o foco em erros conceituais, invetigando, por exemplo, a veracidade, apresentação ou organização de um conceito científico. Outros analisam a estrutura do texto, a questão da sintaxe ou a linguagem do material. Há aqueles que investigam ainda os aspectos ideológicos transmitidos muitas vezes subliminarmente em forma de valores para os alunos ou a imagem da ciência que é propagada para os mesmos (CASSAB, 2003; CARNEIRO; SANTOS; MOL, 2005; FERREIRA; SELLES, 2003; FRACALANZA, 1993).

Esse tipo de análise é, sem dúvida, proveitosa para a realidade brasileira. No entanto, apesar da importância da avaliação de conteúdos realizada por muitos pesquisadores com o intuito de denunciar as deficiências do LDC e sugerir soluções para ampliar a qualidade desse material (BIZZO, 1996; PIMENTEL, 1998; PRETTO, 1985), existem poucos estudos com foco em outros aspectos do LDC, incluindo autores, editores, custos, relação do livro didático com a esfera escolar, escolha do material, questão do uso pelos professores e alunos, formação de professores para a utilização e formas de inovação para o ensino.

Isso significa que ainda temos uma compreensão limitada de todos os elementos envolvidos no desenvolvimento do LDC. Essa falta de compreensão causada pela pouca investigação é em certa medida um obstáculo, pois se soubéssemos mais sobre todos os aspectos, novas ideias e inovações poderiam ser implementadas no ensino de ciências. Apesar de seu caráter polissêmico, a inovação está atrelada a um conjunto de intervenções, decisões com certo grau de intencionalidade e sistematização, que visam a transformar as atitudes, ideias, culturas, conteúdos, modelos e práticas pedagógicas (CARBONELL, 2002; CARDOSO, 2003; FULLAN, 2001).

Ao longo do ano, muitas inovações surgem nas escolas. Garcia

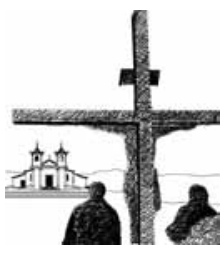


(2009), num estudo sobre a inovação como estratégia de formação contínua de professores de ciências, mostrou que a maioria daquelas que chegam às escolas tem caráter externo e vertical, portanto, são impostas.

As inovações em geral podem ser consideradas internas quando têm origem na própria escola e externas quando se originam fora dela. Elas podem ter sentido vertical, quando surgem de cima para baixo, sendo impostas, ou horizontais, de baixo para cima.

São internas e verticais, dentre outras, aquelas inovações em que os mentores são os coordenadores pedagógicos, o diretor da escola, a orientadora educacional, os inspetores de alunos, a Associação de Pais e Mestres etc. São horizontais e internas aquelas propostas pelos professores, pelos alunos. São verticais e externas aquelas propostas pelo Ministério de Educação, secretarias de educação, mídia, avanço das tecnologias, universidades, através das pesquisas; empresas fabricantes de tecnologias, exigências do mercado de trabalho, mudanças de legislação; reformas educacionais, pressão dos pais, ideologia daqueles que estão no poder (GARCIA, 2009). Há uma variedade de origens das inovações que para serem implementadas dependem do professor, da cultura da escola, de líderes etc. No entanto, inovações horizontais e internas que surgem a partir dos professores e das necessidades pedagógicas são aquelas que apresentam maior probabilidade de sucesso e de continuidade (CARBONELL, 2002).

Assim, as inovações também têm origem e são construídas por meio das pesquisas dentro das universidades. No entanto, se as pesquisas são limitadas ou focam somente um ou outro aspecto do LDC, as possibilidades de inovação no ensino ficam reduzidas.

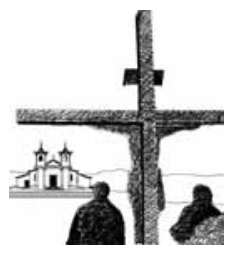

20

Existem três possibilidades de inovação no ensino: aquelas relacionadas à utilização de novos materiais, currículos e tecnologias; o uso das novas abordagens de ensino, estratégias e atividades; e a possibilidade de mudança nas crenças e pressupostos que são subjacentes às práticas pedagógicas (FULLAN, 2001, p. 39).

Considerando essas três dimensões propostas por Fullan, 
quanto às inovações, fomentadas por pesquisas acadêmicas, é necessário conectá-las de forma harmoniosa para que ocasionem mudanças e melhorias prolongadas. Garcia afirma que

não é aconselhável a introdução de uma nova tecnologia, por exemplo, sem, paralelamente, levar os professores ao domínio de novas práticas pedagógicas adequadas ao uso dessa tecnologia e, ao mesmo tempo, alterar suas concepções em relação ao ensino e à aprendizagem (GARCIA, 2010, p. 112).

As inovações sem a combinação dessas três dimensões acabam ficando na superficialidade (FULLAN, 2001).

A partir dessa afirmação de Garcia e considerando, por exemplo, o professor com usuário, ou seja, com o foco no ensino, os estudos sobre o LDC, com intuito de fomentar e promover inovações e mudanças na prática do professor em relação ao uso desse material, deveriam ser integrados e ter novos desenhos.

Uma articulação de pesquisa integrada, a fim de ser utilizada para a construção de inovações no ensino, poderia explorar ao mesmo tempo, por exemplo, as concepções dos professores em relação à introdução de um novo livro, capítulo, ou até mesmo de um conceito a partir de novas estrategias de ensino.

Os estudos tendo o professor como usuário do material são limitados e alguns poucos que são produzidos não são integrados a fim de fomentar inovações no ensino de ciências, considerando as três possibilidades de inovação mencionadas. Carneiro, Santos e Mol afirmam que uma das

funções do livro didático é a de dar suporte ao processo de ensino aprendizagem. No entanto, se conhece muito pouco sobre o cotidiano desse recurso na sala de aula e sobre as concepções dos professores e dos alunos a respeito do mesmo" (CARNEIRO; SANTOS; MOL, 2005, p. 129).

Os autores afirmam ainda que é preciso a organização e o desenvolvimento de um maior número de pesquisas que se

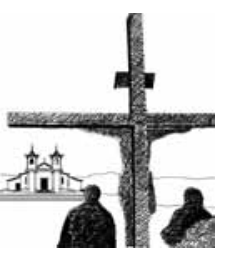

21 
ocupem dos usuários desse material, pois em nosso país o número de estudos é pequeno.

\section{Metodologia}

Este estudo tem o objetivo de analisar a pesquisa sobre o livro didático de ciências no Brasil e também em alguns outros países. Pretendemos verificar as regularidades, semelhanças e diferenças existentes nesse processo de investigação. Paralelamente, almejamos relacionar esses resultados às possibilidades de inovação no ensino.

Analisamos 77 estudos de 24 países retirados dos anais do encontro internacional Critical analysis of school science textbook promovido pela International Organization for Science and Technology Education (IOSTE) e acontecido na Tunísia, em fevereiro de 2007.

A coleta desses dados foi escolhida pelo fato de o evento ser quase que exclusivamente destinado a análise do livro didático de ciências, reunindo pesquisadores de diversos países que se interessam pelo tema. Coletando dados diretamente desses anais, podemos, de certa forma, eliminar questões tais como diferentes fontes de coleta dos artigos para serem analisados.

Dos mais de 150 trabalhos apresentados, 77, de 24 países, foram selecionados a partir de dois critérios: a) o estudo deveria estar relacionado com as disciplinas tradicionais das ciências (biologia, química e física); b) o estudo deveria estar centralizado naquilo que no Brasil chamamos de ensino fundamental e médio (nível educacional elementary school, alunos de 6 a 14 anos, e secondary school, estudantes de 15 a 18 anos).

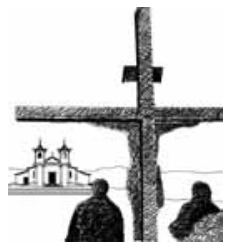

A análise dos dados foi baseada na abordagem da teoria fundamentada (CRESWELL, 2002; STRAUSS; CORBIN, 1990), uma abordagem de tradição qualitativa. Esse enfoque relaciona-se à teoria que é desenvolvida de forma indutiva a partir dos dados coletados.

Em alguns casos, os artigos pertenciam a dois ou mais 22 pesquisadores de mais de um país. Dessa forma, o número de 
nações participantes é maior do que o número de artigos analisados.

Sendo assim, 20,4\% dos estudos vieram da França; 19,5\% da Tunísia; 9,7\% do Brasil; 7,8\% de Portugal; 5,8\% da Grécia e da Turquia; 2,9\% do Líbano, Espanha, Canadá e Polônia; 1,9\% de Marrocos, Hungria, Itália, Cyprus, Alemanha e África da Sul; 1,0\% dos Emirados Árabes, Senegal, Suécia, Coréia do Sul, Finlândia, Lituânia, Eslovênia e Eslováquia.

A Europa é o continente de maior representação de países, no entanto existem artigos analisados de outros continentes também. Um procedimento adotado em relação às análises foi o de separar os artigos em dois grupos: os provenientes do Brasil (dados do Brasil - DB) e aqueles dos outros países (dados de outros países - DOP).

Inicialmente realizamos a apreciação com uma leitura global e generalizada de todos os artigos. Nessa primeira fase, utilizamos a codificação aberta por meio da segmentação dos dados para permitir as análises pretendidas. Na segunda etapa, por meio dessa filtragem dos dados e análises, com a utilização de códigos e descritores, identificamos as categorias abrangentes. A partir desses códigos classificados em categorias, procuramos por regularidades, similaridades e diferenças entre os artigos. Por fim, reduzimos as categorias para a identificação de temas comuns.

Estabelecemos quatro categorias:

1) Autores e editores - esse grupo foi dividido em duas subcategorias: a) critérios para a escolha de conteúdos conceituais; b) critérios para a escolha das ilustrações. Nessas subcategorias, agrupamos as pesquisas desenhadas para saber quais os critérios foram utilizados na seleção de conhecimentos e de imagens, mapas, gráficos incluídos nos livros didáticos.

2) Professores como usuários - esse grupo foi dividido em duas subcategorias: a) o processo de escolha dos livros didáticos; b) as formas de utilização do LDC em sala de aula. Nessas categorias, reunimos estudos cujos objetivos eram respectivamente conhecer os critérios utilizados pelos professores para escolher o material e como os professores utilizavam esses materiais em sala de aula.

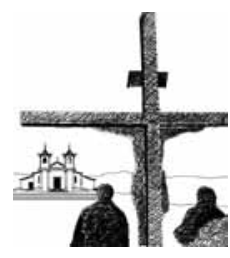


3) Alunos como usuários - esse grupo também foi dividido como as categorias acima: a) os modos como os LDC são usados, que reuniu os trabalhos que investigaram como os alunos utilizaram o material em sala de aula; $b$ ) aprendizagem do aluno, em que foram agrupadas as pesquisas que procuraram compreender aspectos da aprendizagem dos estudantes relacionados a determinados conteúdos e conceitos contidos nos livros didáticos.

4) Conteúdo do LD - esse grupo foi dividido em cinco subcategorias: a) conteúdos conceituais, aqui agrupamos os trabalhos que investigaram a apresentação de conceitos (por exemplo, como um conceito é apresentado em um determinado capítulo do livro), organização de conceitos (por exemplo, como um ou mais conceitos são organizados para serem apresentados aos alunos), erros conceituais (por exemplo, análise do número de erros encontrados no livro), transposição didática (por exemplo, como um conhecimento científico é transformado para ser ensinado em sala de aula), estrutura do texto (por exemplo, como os conceitos são organizados e apresentados na estrutura de linguagem), sintaxe (por exemplo, como o palavras em uma frase e as sentenças são organizadas de modo a auxiliar a compreensão do aluno) e linguagem (por exemplo, como a linguagem é organizada no material); b) a ideologia e os valores do livro (por exemplo, como os valores são transmitidos); c) imagem da ciência, aqui agrupamos os trabalhos que retratavam a imagem da ciência; d) ilustrações (por exemplo, como gráficos ou mapas podem ajudar os estudantes a entender o contexto); e) concepção de ensino (por exemplo, como é explorada a concepção de educação no material). Quando um estudo era incluído nessa última categoria, também analisamos a área do estudo (física, química, biologia), o assunto e o nível de escolaridade.

A fim de detalhar ainda mais os dados, os trabalhos incluídos na subcategoria "ideologia e valores" (b) e "imagem da ciência" (c), que de uma maneira ou de outra também analisaram conteúdos, foram separados da subcategoria "conteúdos conceituais" (a). No entanto, na análise global das frequências, as subcategorias (b) e 
(c) foram incluídas na subcategoria (a).

Um mesmo estudo algumas vezes apresentava mais de um objetivo e, portanto, ele foi incluído em mais de uma categoria, o que explica a diferença entre o número total de estudos $(\mathrm{N}=77)$ e a frequencia dos estudos considerados $(n=140)$.

Analisamos também, em todos os artigos, o tipo de metodologia utilizada, o número de pesquisadores envolvidos na pesquisa, o nível educacional em que o estudo estava localizado e a nacionalidade da pesquisa.

\section{Resultados e discussão}

Os resultados são apresentados inicialmente de acordo com as categorias e subcategorias. Os dados de outros países (DOP) e do Brasil (DB) estão sintetizados na TAB. 1 e TAB. 2.

\section{TABELA 1}

Categorias e frequências dos outros países

\begin{tabular}{|c|c|c|c|}
\hline & Categorias & Subcategorias & Frequência \\
\hline \multirow[t]{2}{*}{1} & \multirow[t]{2}{*}{$\begin{array}{c}\text { Autores } \\
\text { e editores }\end{array}$} & $\begin{array}{l}\text { Critério para a escolha } \\
\text { dos conteúdos conceituais }\end{array}$ & 01 \\
\hline & & Critérios para a produção das ilustrações & 01 \\
\hline \multirow{2}{*}{2} & \multirow{2}{*}{$\begin{array}{l}\text { Professores } \\
\text { como usuários }\end{array}$} & O processo de escolha do LDC & 02 \\
\hline & & Modos de uso do LD na sala de aula & 07 \\
\hline \multirow[b]{2}{*}{3} & \multirow{2}{*}{$\begin{array}{l}\text { Estudantes } \\
\text { como usuários }\end{array}$} & Usos do LDC & 02 \\
\hline & & Aprendizagem do aluno & 04 \\
\hline \multirow{6}{*}{4} & \multirow{5}{*}{$\begin{array}{l}\text { Conteúdo } \\
\text { do LD }\end{array}$} & Conteúdos conceituais & 50 \\
\hline & & Ideologia e valores & 18 \\
\hline & & Imagem da ciência & 02 \\
\hline & & Ilustrações e imagens & 33 \\
\hline & & Concepção educacional & 10 \\
\hline & Total & & 130 \\
\hline
\end{tabular}

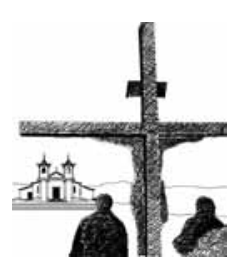

25 
TABELA 2

Categorias e frequências da realidade brasileira

\begin{tabular}{cccc}
\hline & Categorias & Subcategorias & Frequência \\
\hline 2 & $\begin{array}{c}\text { Professores como } \\
\text { usuários }\end{array}$ & O processo de escolha do LDC & 01 \\
\hline 4 & $\begin{array}{c}\text { Conteúdo } \\
\text { do LD }\end{array}$ & Conteúdos conceituais & 08 \\
\cline { 2 - 4 } & Concepção educacional & 01 \\
\hline
\end{tabular}

Existem diferentes tipos de pesquisa sobre livros didáticos de ciência em diversos contextos socioculturais. Os dados possibilitaram ampliar os debates e as discussões sobre a atual situação das pesquisas sobre o LDC no Brasil e em alguns países.

Existem poucos estudos focando as categorias 1, "autores e editores" e 3, "estudantes como usuários", nos países analisados. No Brasil, por exemplo, na amostra investigada, não encontramos nenhum.

Tendo como foco os professores como usuários desse material, poucos estudos (09, DOP) e (01, DB) foram encontrados nos dados analisados. De acordo com Carneiro, Santos e Mol (2005), apesar da existência de um grande número de estudos que investigam os livros didáticos de ciências, o número de pesquisas examinando, por exemplo, as concepções dos professores e alunos em relação a esse material ou o cotidiando do LDC na sala de aula ainda é inexpressivo.

É possível ver que a maioria dos estudos dos DB (90\%) e dos DOP $(86,9 \%)$ concentrou-se nos conteúdos do LDC (categoria 4 ).

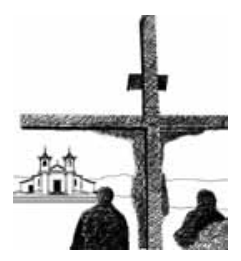

26 Dentro dessa categoria, nos dados DOP, quase $44,3 \%$ investigaram o conteúdo conceitual; 29,2\%, as ilustrações e imagens, e 8,9\% examinaram a concepção educacional do livro de ciências. Quanto à realidade brasileira, observamos que ela não diverge muito: $88,9 \%$ dos estudos estão nos conteúdos conceituais e 11,1\%, na concepção de educação do material.

Esses resultados apresentados mostram que em muitos países 
a pesquisa sobre o LDC está assentada nos conteúdos, sobretudo, nos conceituais. A realidade brasileira também apresentou a mesma característica. Esse resultado já havia sido sinalizado no Brasil através de alguns estudos (CASSAB, 2003; CARNEIRO; SANTOS; MOL, 2005; FERREIRA; SELLES, 2003; FRACALANZA, 1993; JOHNSEN, 1996). Assim, essa característica da pesquisa relacionada aos conteúdos não é somente uma perspectiva local, mas também de vários outros países.

O foco prioritário das pesquisas na avaliação dos conteúdos conceituais nos permite somente uma compreensão limitada de todos os elementos envolvidos no desenvolvimento do LDC. Esse foco tem sua justificativa relacionada ao papel dos conteúdos e à sua exatidão no ensino de ciências. Isso é importante no contexto brasilerio devido às deficiências desse material. Essas deficiências já foram apontadas por muitos pesquisadores que propuseram melhorias na qualidade (BIZZO, 1996; PIMENTEL, 1998; PRETTO, 1985). No entanto, é possível dizermos que há ainda um longo caminho para se afirmar que a pesquisa pode trazer uma compreensão ampla e profunda do que tem sido considerado uma abordagem "precisa" para alguns conceitos. A simples comparação com versões acadêmicas muitas vezes não é razoável, já que não se considera os procedimentos de transposição didática, por exemplo.

Em relação à área do estudo, as pesquisas estavam distribuídas da seguinte forma: $42,3 \%$ em biologia, tendo como temas mais estudados: educação sexual, educação ambiental e ecologia; 15,5\% em Física, explorando temas como energia; $6,9 \%$ em química, examinando temas como gases e soluções; $12,7 \%$ em ciências em geral.

Os dados também mostraram que um pequeno grupo de pesquisadores tem se dedicado a entender como as imagens, fotos e ilustrações são apresentadas; como elas podem ajudar na aprendizagem dos alunos ou quais os valores são transmitidos por elas.

Em relação ao nível de escolaridade em que o estudo estava

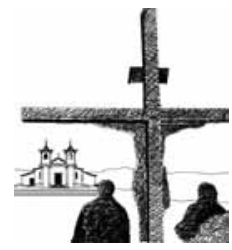


envolvido, 22,2\% estavam centralizados no ensino fundamental (alunos de 6 a14 anos); 57,2\%, no ensino médio (alunos de 15 a 18 anos) e $20,1 \%$ em ambos.

A análise da abordagem metodológica mostrou que 79,3\% dos estudos foram baseados em métodos qualitativos; 3,9\%, no quantitativo e $16,8 \%$ utilizaram as duas metodologias.

Alguns estudos foram realizados por grupos de pesquisa já estabelecidos, enquanto outros foram feitos por pesquisadores que se uniram através de um projeto comum como é o caso do projeto Biohead biology, health and environmental education for better citizenship. Outros ainda foram desenvolvidos por pesquisadores independentes. Os resultados mostraram que cerca de $35 \%$ dos trabalhos apresentados foram produzidos apenas por um pesquisador e cerca de $28 \%$ dos estudos tinham mais de três autores.

Finalmente, a partir da análise de todos os estudos, aproximadamente $21 \%$ eram provenientes da França; quase $20 \%$ ,da Tunísia e quase 10\%, do Brasil.

\section{Implicações finais}

Os resultados apresentados mostraram que em muitos países e também no Brasil a pesquisa sobre o LDC está assentada nos conteúdos.

A quase totalidade da pesquisa, nessas realidades estudadas, estava focada no estudo dos conteúdos, o que de certa forma limita nossa compreensão em todos os aspectos que envolvem o LDC e ao mesmo tempo dificulta a construção de inovações no ensino de ciências.

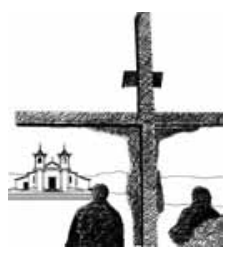

É importante superar o senso comum de que é simples realizar estudos sobre os livros didáticos, e que já temos todas as ferramentas teóricas para realizar essa tarefa. Johnsen (1996) vai mais além e, usando uma analogia do caleidoscópio, sugere que as análises de livros didáticos devem ser mais integradas e sincronizadas com todas as partes da cadeia que envolve dentre 
outras coisas, a elaboração de livro, a produção e os usuários.

Em relação ao uso do LDC pelo professor no ensino, todos os estudos analisados - que eram proveniente de outros países, pois nos dados do Brasil não encontramos esse tipo de estudo na amostra analisada - apresentavam desenhos de pesquisas não integrados. Portanto, tinham pouca relevância a partir da perspectiva de fomentar inovações no ensino, considerando a associação das três possibilidades de inovação propostas por Fullan (2001).

Os estudos sobre a inovação no ensino sugerem que a implantação dessa seja realizada de forma integrada. Portanto, as pesquisas produzidas com o intuito de fomentar inovações no ensino, em relação ao professor como usuário do LDC, necessitariam ter esse caráter integrado também.

As análises aqui apresentadas sugerem, aos interessados em pesquisar sobre LDC, modelos de pesquisas integrados para que esses apresentem subsídios para as inovações no ensino de ciências.

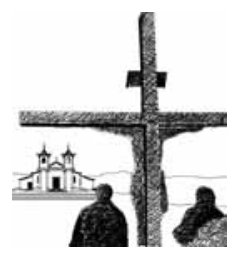




\section{Referências}

BERNARD, S.; CLÉMENT, P. Teaching human reproduction and sexuality: a historical approach in France since 1950. In: INTERNATIONAL HISTORY, PHILOSOPHY, SOCIOLOGY AND SCIENCE TEACHING CONFERENCE, 8., 2005, Leeds. Proceedings... Disponível em: <http:/ / www.ihpst2005.leeds. ac.uk/papers/Bernard_Clement.pdf>. Acesso em: 15 jun. 2006.

BIZZO, N. Graves erros de conceito em livros didáticos de ciências. Ciência Hoje, Rio de Janeiro, v. 21, n. 121, p. 26-34, jun. 1996.

Reflections upon a national program assessing science textbooks: what is the importance of content in science education? In: BIZZO, N. et al. (Orgs.). SYMPOSIUM OF THE INTERNATIONAL ORGANIZATION FOR SCIENCE AND TECHNOLOGY EDUCATION - IOSTE, 10, 2002, Foz do Iguaçu (Brasil) Proceedings..., Foz do Iguaçu, 2002. p. 710-720.

BIZZO, N.; TOLENTINO-NETO, L. C. B.; GARCIA P. S. What do teachers expect from the textbooks? The study of the process of choice of textbooks in Brazilian public schools. In: INTERNATIONAL MEETING ON CRITICAL ANALYSIS OF SCHOOL SCIENCE TEXTBOOK - IOSTE, 2007, Hammamet. Proceedings... Tunis: University of Tunis, 2007. v. 1. p. 311-319.

BIZZO, N. et al. Brazilian science textbooks and canonical science. In: INTERNATIONAL MEETING ON CRITICAL ANALYSIS OF SCHOOL SCIENCE TEXTBOOK - IOSTE, 2007, Hammamet. Proceedings... Tunis: University of Tunis, 2007. v. 1. p. 301-309.

CARBONELL, J. A aventura de inovar: a mudança na escola. Porto Alegre: Artes Médicas, 2002.

30 
CARDOSO, A. P. Educação e inovação. Millenium on-line, Viseu, n. 6, mar. 1997. Disponível em: <http:/ /www.ipv.pt/ millenium/pce6_apc.htm>. Acesso em: 04 fev. 2003.

CARNEIRO, M. H. S.; SANTOS, W.; MOL, L. P. Livro didático inovador e professores: uma tensão a ser vencida. Revista ENSAIO - Pesquisa em Educação em Ciências, Belo Horizonte, v. 7, n. 2, 2005.

CASSAB, M. Significando o livro didático: com a palavra, os professores de ciências. 2003. Dissertação (Mestrado em Formação Profissional e Docente nas Ciências e na Saúde) Núcleo de Tecnologia Educacional para a Saúde, Universidade Federal do Rio de Janeiro, Rio de Janeiro, 2003.

CARVALHO, G.; SILVA, R.; CLÉMENT, P. Historical analysis of portuguese primary schoool textbooks on the topic of digestion. In: INTERNACIONAL HISTORY, PHILOSOPHY, SOCIOLOGY AND SCIENCE TEACHING CONFERENCE, 8., Leeds, 2005. Proceddings... Disponível em: <http://www. ihpst2005.leeds.ac.uk/papers/Carvalho_Silva_Clement.pdf>. Acesso em: 15 jun. 2006.

CLÉMENT, P. Introducing the cell concept by both animal and plant cells: a historical and didatical approach. In: INTERNACIONAL HISTORY, PHILOSOPHY, SOCIOLOGY AND SCIENCE TEACHING CONFERENCE, 8., Leeds, 2005. Proceddings... Disponível em: <http:/ / www.ihpst2005.leeds. ac.uk/papers/Carvalho_Silva_Clement.pdf>. Acesso em: 15 jun. 2006.

CHOPPIN, A. História dos livros e das edições didáticas: sobre o estado da arte. Educação \& Pesquisa, São Paulo, v. 30, n. 3, p. 549-566, 2004.

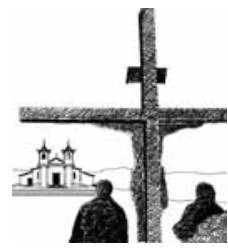


CRESWELL, J. W. Educational research: planning, conducting, and evaluating quantitative and qualitative research. New Jersey: Pearson Education, Inc. 2002.

EL-HANI, C. N.; ROQUE, N.; ROCHA, P. L. B. da. Brazilian High School Biology Textbooks: Results from a National Program. In: INTERNATIONAL MEETING ON CRITICAL ANALYSIS OF SCHOOL SCIENCE TEXTBOOKS - IOSTE, 2007, Hammamet. Proceedings ... Tunis: University of Tunis, 2007. v. 1. p. 505-516.

FERREIRA, M. S.; SELLES, S. E. A produção acadêmica brasileira sobre livros didáticos em ciências: uma análise em periódicos nacionais. In: ENCONTRO NACIONAL DE PESQUISA EM EDUCAÇÃO EM CIÊNCIA, 4., Bauru. Anais... Bauru: [s. n.], 2003. 1 CD-ROM.

FRACALANZA, H. O que sabemos sobre os livros didáticos para o ensino de ciências no Brasil. 1993. Tese (Doutorado em Metodologia de Ensino) - Faculdade de Educação, Universidade Estadual de Campinas, Campinas, 1993.

FRACALANZA, H.; MEGID NETO, J. (Orgs.). O livro didático de ciências no Brasil. Campinas: Editora Komedi, 2006.

FULLAM, M. The new meaning of educational change, $2^{\text {nd }}$ ed. New York: Teaches' College Press, 2001.

\section{FUNDAÇÃO NACIONAL DE DESENVOLVIMENTO DA} EDUCAÇÃO. Dados estatísticos sobre o livro didático - 2010. Disponível em: <http://www.fnde.gov.br/index.php/pnlddados-estatisticos>. Acesso em: 19 fev. 2011. . Dados estatísticos sobre a alimentação escolar - 2010. Disponível em: <>. Acesso em: 19 fev. 2011. 
GARCIA, P. S. Inovação e formação de professores no contexto da escola pública. In: (Org.). Debates e contribuições sobre a escola pública: de professor para professor. São Paulo: Editora LCTE, 2009. pp. 45-66.

. Inovações e mudanças: por que elas não acontecem nas escolas? Uma macroanálise envolvendo professores de ciências. São Paulo: Editora LCTE, 2010.

GAYÁN, E.; GARCÍA, P. E. Como escoger un libro de texto? Desarrollo de un instrumento para evaluar los libros de texto de ciencias experimentales. Enseñanza de las ciencias, Murcia/ Espanha, Número Extra, V Congresso, p. 249-250, 1997.

JOHNSEN, E. Livros de texto em el calidoscopio. Estudio crítico de la literatura y la investigación sobre los textos escolares. Barcelona: Pomares-Corredor, 1996.

HÖFFLING, E. M. Notas para discussão quanto à implementação de programas de governo: em foco o Programa Nacional do Livro Didático. Educação e Sociedade, São Paulo, v. 21, n. 70, p. 159-170, 2000.

HUBISZ, J. Middle-school texts don't make the grade. Physics Today, New York, v. 56, n. 5, p. 50-54, 2003. Disponível em: <http://physicstoday.org/journals/doc/PHTOAD-ft/vol_56/ iss_5/50_1.shtml?bypassSSO=1>. Acesso em: 15 jun. 2006.

KNAIN, E. Ideologies in school science textbooks. International Journal of Science Education, v.3, n. 23, p. 319-319, 2001.

MARTINS, I. Imagens no livro didático e na sala de aula de ciências. Rio de Janeiro: Núcleo de Tecnologia Educacional para a Saúde, UFRJ/Fundação Carlos Chagas de Apoio à Pesquisa do Estado

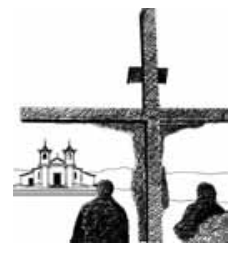


do Rio de Janeiro, 2003. Relatório de Pesquisa.

NIAZ, M. et al. Arguments, contradictions, resistances and conceptual change in students understanding of atomic structure. Science Education, n. 86, p. 505-525, 2002.

PIMENTEL, J. R. Livros didáticos de ciências: a física e alguns problemas. Caderno Catarinense de Ensino de Física, Florianópolis, v. 15, n. 3, p. 308-318, 1998.

PRETTO, N. L. A ciência nos livros didáticos. Campinas: Editora da UNICAMP; Salvador: CED/UFBA, 1985.

STRAUSS, A. L.; CORBIN, J. M. Basics of qualitative research: grounded theory procedures and techniques. Thousand Oaks, California: Sage Publications, 1990.

TASKIN, Ö. Constructivist science text books \& curriculum hidden (abused) agenda or the best practice? Turkey case. In: INTERNATIONAL MEETING ON CRITICAL ANALYSIS OF SCHOOL SCIENCE TEXTBOOK, IOSTE Proceddings... Tunis: University of Tunis, 2007. p. 988-998.

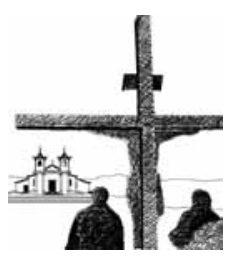




\title{
Research on science textbook and innovations in teaching
}

\begin{abstract}
This study aims to analyze the research with the science textbook (LDC) in Brazil and also in some countries and, simultaneously, to relate these results to the innovation' possibilities in Science education. We analyzed 77 studies from 24 countries. In these studies it were analyzed paper's focus, the type of research methodology used, the number of researchers involved, the area of study, the focus of the topic being investigated, the educational level of the study, and the nationality of the research. The results showed that most studies of other countries $(86.9 \%$ ) and $90 \%$ of Brazil had the focus on the contents of the LDC. These studies were more concentrated in Biology $(42.3 \%)$ and centralized on secondary level of education. The researchers used, principally, qualitative methodologies and the majority of papers came mainly from France, Tunisia, and Brazil. The results are relevant to subsidize future research on this material.
\end{abstract}

Keywords: Science textbook; science education, research on science textbooks.

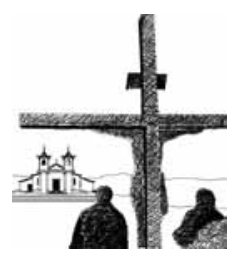

